\title{
Los conventos de la Nueva España del siglo XVII como espacios de desarrollo femenino: el caso del Convento de San Jerónimo de México.
}

The 17 century New Spain convents as spaces for woman development: the case of the Convent of San Jeronimo de Mexico.

\section{Guillermo Schmidhuber de la Mora}

Departamento de Letras / Universidad de Guadalajara (MÉXICO)

CE: schmidhuberg@gmail.com ID ORCID: 0000-0001-8419-5228

DOI: $10.32870 /$ sincronia.axxiii.n76.21b19

Recibido: 07/03/2019

Revisado: $12 / 03 / 2019$

Aprobado: 13/05/2019

\section{RESUMEN}

Propuesta para comprender los conventos novohispanos de los siglos XVII y XVIII como lugares en que las monjas lograban oportunidades para desarrollar sus habilidades personales, tales como aprender a leer y a escribir y a hacer múltiples labores manuales, gracias a la motivación grupal podían alcanzar un grado considerable de autoestima y de auto realización. Este estudio presenta el caso del Convento de San Jerónimo de México con información acerca del apoyo que todas las monjas tenían para desarrollarse y aprender a leer y escribir, hacer manualidades y cocina creativa. En este convento vivió Sor Juana Inés de la Cruz (1648-1695), pero su caso es excepcional por su autodidactismo y su trabajo intelectual.

Palabras clave: Sor Juana Inés de la Cruz. Sociedad Novohispana. Conventos católicos. 


\section{Abstract:}

This is a proposition to understand the New Spain convents during the 17th and 18th as places in which the nuns managed to find opportunities to develop their personal skills, like learning how to read and write and performing multiple manual work, as result of group motivation they could achieve a considerable degree of self-esteem and self realization. This study presents the case of the Convent of San Jeronimo de Mexico informing about the help that all the nuns had to develop themselves and learn how to read and write, do crafts and creative cooking. In this convent Sister Juana Ines de la Cruz lived (1648-1695), but her case was an exceptional one due to her selfeducation and her intellectual work.

Keywords: Sister Juana Ines de la Cruz. New Spain society. Catholic convents.

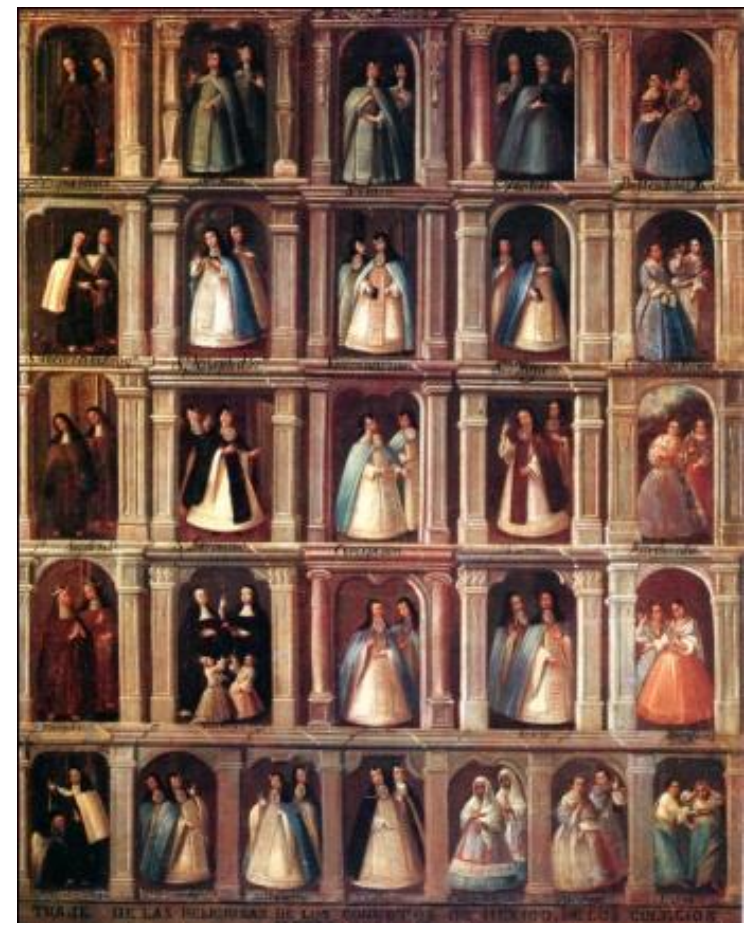

Hábito de San Jerónimo lugar 12ㅇ․ Óleo sobre tela, s.f., siglo XVIII, Museo Nacional del Virreinato, Tepozotlán (Tapia, 1993, p. 202). 
El monasterio de San Jerónimo fue la sexta fundación conventual de la ciudad de México entre 1584 y 1585. Precedido por los Conventos de la Concepción, el Convento de Nuestra Señora de Balvanera, el de Regina Cœli, el de Santa Clara y el de Jesús María (Amerlinc y Ramos Medina). La fundación de este nuevo convento fue posible gracias al apoyo del rey de España Felipe II y la petición de Isabel de Guevara, viuda que era parte de una familia acaudalada, quien donó más de veinte mil pesos para el claustro bajo la regla de san Agustín.

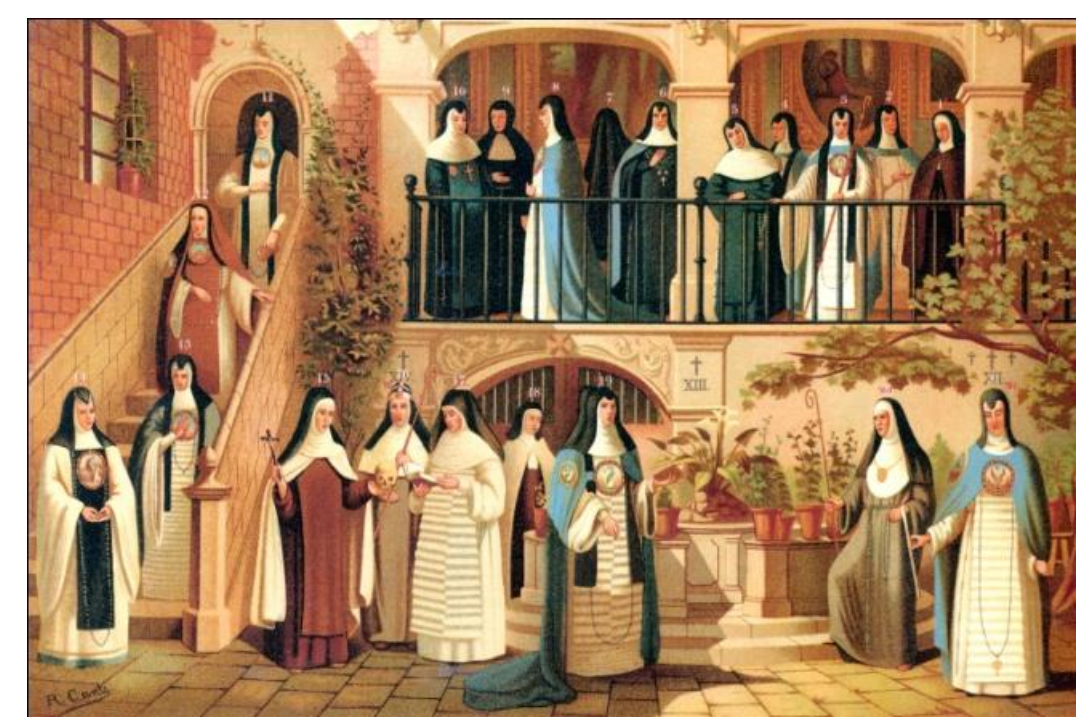

Hábito de San Jerónimo primera a la izquierda. Oleo de R. Cruz (Tapia, 1993, p. 210).

Debido a la cercanía temporal con el periodo de conquista, en el siglo XVI no había el número de religiosas ya formadas y difícil sería invitarlas de España; por lo que el arzobispo de México don Pedro Moya de Contreras (1574-1589), seleccionó a cuatro monjas provenientes del Real Convento de la Concepción, el más antiguo de la ciudad. El día de la fundación, el 29 de septiembre de 1585, las religiosas anteriormente concepcionistas viajaron veladas en compañía del prelado, en medio de fiestas y algarabías al parcialmente construido claustro: María de la Concepción, priora y vicaria de coro y maestra de novicias, quien se hizo jerónima pero posteriormente regresó a su convento con permiso papal; Catalina de Santa Inés, portera mayor y tornera; Juana de la Concepción, vicaria de casa y tornera mayor y Cecilia de San Buenaventura segunda portera y tornera. 
Como todos los conventos de monjas en la ciudad de México, el convento de San Jerónimo, estuvo desde su fundación gobernado por el arzobispo de México y llevó la advocación de Nuestra Señora de la Expectación, aunque prácticamente no fue reconocido como tal; su patrona fue Santa Paula en honor de aquella matrona romana mecenas de San Jerónimo, con ese nombre fue identificado el convento pero también con el de San Jerónimo. La orden jerónima seguía la Regla de San Agustín y se caracterizaba por ser menos austera que las carmelitas descalzas en cuyo convento había estado Juana Inés por tres meses y luego salir; sin embargo, tres meses después ingresó en el claustro jerónimo. En ese nuevo convento, con el permiso de la priora podían también contar con libros, imágenes, objetos religiosos diversos y hasta convivir internamente con parientas, como sor Juana lo hizo con dos de sus medias hermanas, además de criadas y esclavas. Bien sabemos que cuando ingresó al noviciado la acompañó una esclava que le había donado su madre doña Isabel Ramírez. Se trataba de una mulata "su esclava, nombrada Juana de San José, hija de Francisca de Jesús, asimismo mulata, esclava de dicha su madre para que le sirviese", como se menciona en el Documento de la Licencia a sor Juana Inés de la Cruz para que venda una esclava de su propiedad con fecha del 6 de junio de 1684 (Cervantes, 22-23).

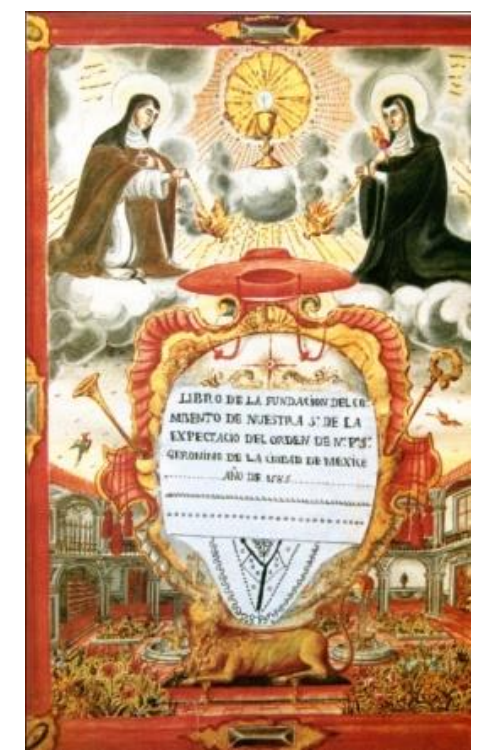

Portada Libro de la Fundación del Convento de San Jerónimo, 1585 (Tapia, 1993, p. 191) 
Convivir con monjas dentro del Claustro de San Jerónimo debe haber sido un cuidado más que arduo como también una gran satisfacción. El convento de San Jerónimo llegó a tener cien monjas en 1661 cuando había pasado setenta y seis años de su fundación. La mayor población fue entre 1644 y 1651; el año más denso fue 1648 en que hubo 120 monjas. El año en que Juana Inés profesó (1669), el convento contaba con 88 monjas en el claustro (con ella); y en el año de su muerte (1695) pudieron asistir 85 monjas a su entierro en el coro bajo del templo de San Jerónimo (Libro de Profesiones 29). Muchas causas hacían singular las relaciones entre las monjas: el profesar en el mismo periodo o el congeniar con la misma priora, el tener salud o no tenerla, el preferir el imán de la cercanía o el polo de la solitud.

La visión liberal del siglo XIX pensó que los conventos eran espacios carentes de libertad e intelectualmente no nutrientes, y si ya la mujer tenía un espacio social muy por debajo del ocupado por el criollo, bajo la sofocación del reglamento de San Agustín o San Francisco les impedía el crecimiento humano debido. Fue una apreciación errónea porque los conventos eran más espacios de creación que los hogares españoles. La mayoría de las monjas aprendían a leer, escuchaban piezas de oratoria religiosa y dedicaban horas a labores al bordado y de alta cocina, además tenían clases tanto de religión como de esparcimientos creativos, tales como la música y la pintura.

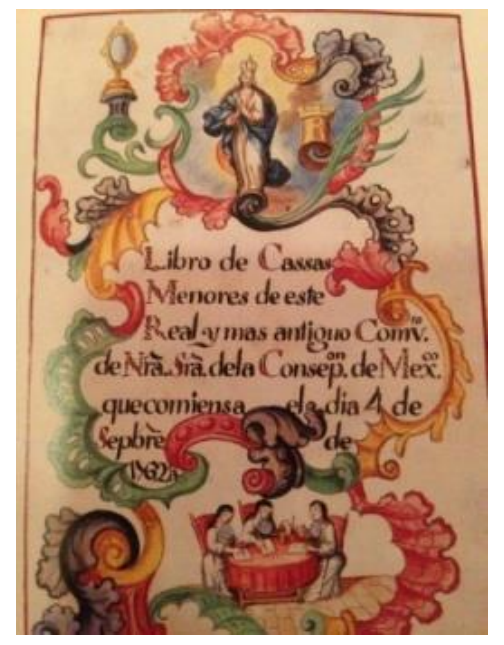

Portada de un libro perteneciente al convento concepcionista, 1762, Colección padre José G. Herrera. ${ }^{1}$

\footnotetext{
${ }^{1}$ Agradezco al padre José Gerardo Herrera que me haya facilitado la foto tomada por él de tan magnífico libro.
} 
Sor Juana logró tiempo para escribir una cuantiosa obra poética y dramática. En sus horas diurnas libres para la creación entre las citas para rezar con la comunidad y los menesteres de contadora y secretaria, cuando fungió en esos cargos; además, tiempo libre en horas robadas al sueño en el solaz de su celda. Definitivamente las mujeres pensantes no eran ajenas a la vida conventual. San Jerónimo había logrado traducir la Vulgata porque recibió el mecenazgo de varias damas, como santa Paula y su hija san Eustaquio, ellas solventaron los gastos de viaje para la investigación en tierra santa. Así que el hecho que una monja supiera leer o escribir no era insólito. Paralelamente, como antes se mencionó, en todo convento había interés por el dibujo y la música. Se han conservado manuscritos con decoraciones preciosas elaboradas por manos monjiles. Bien es recordada la presencia de coros en los conventos femeninos y se mencionan grupos musicales con instrumentos diversos tocados por religiosas. Las labores femeninas de tejido y bordado han dejado muestras que hoy están en museos como el Franz Mayer de ciudad de México.

La amistad entre los diversos conventos fue un eslabón social muy importante. Desde su fundación el convento de San Jerónimo llevó gran amistad con el Convento Concepcionista de Regina Cœlli no únicamente porque sus predios colindaban, sino como recuerdo de las cuatro monjas Concepcionistas que fueron a entrenar a las iníciales vocaciones jerónimas en los tres años primeros después de su fundación (Peñalosa, 1997, p. 48). Al restaurar el claustro de San Jerónimo entre los escombros se encontró el cacharro de un plato con el nombre del convento Regina Cœlli, prueba de la comunicación intraconventual, acaso con el regalo de una sabrosa vianda. ${ }^{2}$

Existe un manuscrito que ha sido publicado bajo el nombre de Libro de cocina Convento de San Jerónimo (hoy propiedad de don Joaquín Cortina), innegable recetario del claustro; pero al no ser la letra del siglo XVII, imposible que fuera original de sor Juana como se ha pretendido con la selección y transcripción suya, aunque eso no le quita nada como prueba de la sabrosura culinaria.

\footnotetext{
${ }^{2}$ Los logros concepcionistas en el campo culinario quedaron patentes por el obsequio que estas monjas enviaron a Agustín de Iturbide de "chiles del embeleso de la libertad" con los colores trigarantes. El Emperador agradeció el obsequio con un enconchado religioso de San Nicolás a la madre María Antonia y al reverso escribió esta atinada frase libertaria. Este cuadro y la nota firmada están hoy en posesión del Pbro. José Gerardo Herrera.
} 
El santoral ofrecía hacer de cada día uno distinto, y estaban la cuelgas de las prioras o la visita anual de los virreyes y del arzobispo. El teatro no era actividad negada, sino era parte del jolgorio del claustro (Basarte, 1756; Frederick Luciani, 2008). Los logros del convento concepcionista en el campo culinario quedaron patentes por el obsequio que estas monjas enviaron a Agustín de Iturbide de "chiles del embeleso de la libertad" con los colores trigarantes. El Emperador agradeció el obsequio con un enconchado religioso de San Nicolás a la madre María Antonia y al reverso del cuadro escribió esta atinada frase libertaria. El enconchado y la nota firmada están hoy en posesión del Pbro. José Gerardo Herrera.

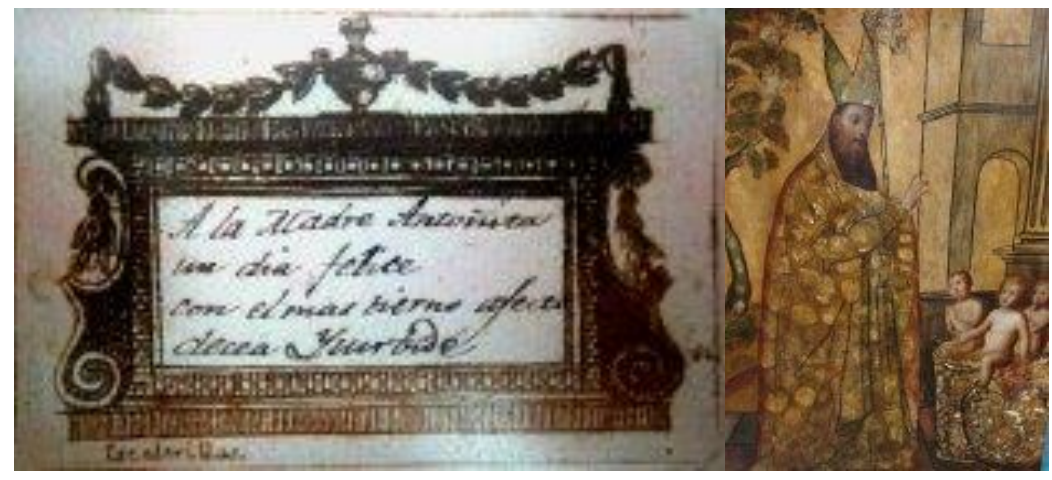

Obsequio de Agustín de Iturbide a las monjas concepcionistas. Colección padre José Gerardo Herrera.

El convento de San Jerónimo vivió en 1686 un evento religioso de gran importancia al aceptar el voto y juramento de la Inmaculada Concepción. Para dejar un memorial del evento, las religiosas firmaron el siguiente documento que fue adornado con preciosa caligrafía y dibujos alusivos. El original hoy se localiza en la biblioteca del Centro de Estudios de Historia de México CARSO-SLIM y es un ejemplo del desarrollo artístico monjil. 


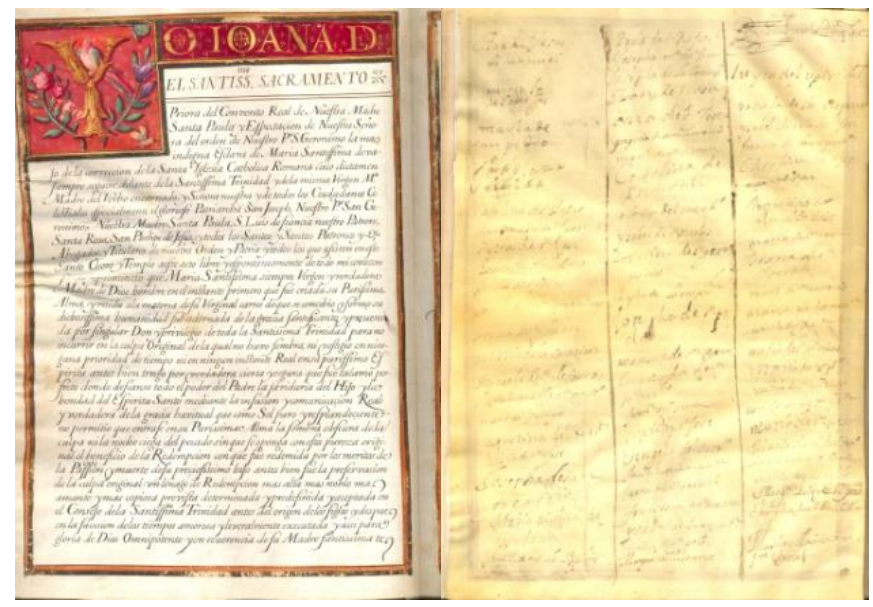

Documento del Juramento, Convento de San Jerónimo, 1686 (Ramos, 2011), Centro de Estudios de Historia de México CARSO. Ciudad de México.

Estudiar los conventos novohispanos en esencial para entender el periodo virreinal (Ramos, 2011 y 2013). Uno de los espacios esenciales del convento de San Jerónimo era el coro, alto y bajo, lugar donde recibían el hábito de novicias y hacían su profesión, y donde realizaban sus oraciones y observaban la misa mediante un enrejado; además el coro bajo estaba el lugar en donde enterraban a las monjas bajo el piso. El coro se encontraba en el extremo contrario al altar y los feligreses ingresaban a la iglesia por una puerta lateral a la mitad de la nave bajo un pórtico con la escultura del santo patrono. Estos espacios hasta hoy persisten y pueden ser visitados. El acceso del templo al coro y al claustro se realizaba por una puerta que permanecía siempre cerrada, pero por mediación de una puertecilla llamada cratícula, se daba la comunión a las enclaustradas para ni ver ni ser vistas. Las iglesias conventuales de Santa Teresa La antigua y de 'Las lorenzas' tienen la misma distribución interior y pueden ser hoy visitadas. ${ }^{3}$

La iglesia de San Jerónimo tenía además de la puerta lateral mencionada, otra entrada directa a la sacristía. La única torre se levantaba orgullosa con un diseño original de Cristóbal de Medina Vargas (1635-1699), quien la construyó en 1665; es el mismo arquitecto que construyó las

\footnotetext{
${ }^{3}$ Imposible no citar en este libro de redes sociales la historia del Pbro. Bernardo de Balbuena y su Grandeza Mexicana (1604), poema que fue dedicado a manera de carta a doña Isabel de Tobar y Guzmán, quien tras la muerte de su esposo y la entrada en la Compañía de Jesús de su único hijo, viajaría de San Miguel de Culiacán a la ciudad de México a tomar el hábito jerónimo en el convento de San Lorenzo.
} 
portadas salomónicas de la catedral metropolitana (Fernández, 2002). La misma arquitectura del claustro de San Jerónimo invitaba a cierta vida particular En general, los conventos eran de dos diseños: de vida Comunitaria — como en las órdenes mendicantes, como las agustinas, carmelitas, franciscanas, también calificados de 'descalzas', quienes compartían el refectorio para comer y celdas comunitarias en los espacios del claustro; diferentes eran los conventos de vida Particular — calificados de 'calzadas', que tenían celdas individuales como casitas conglomeradas dentro de los muros de clausura, como las jerónimas, dominicas y concepcionistas.

El claustro era una pequeña ciudad con casitas, capillas, plazoletas, escaleras y callejones dentro de otra ciudad mayor: un pueblito medieval dentro de una ciudad barroca. La monja transcurría su vida en su espacio privado. Sor Juana Inés compró en 1692 por trescientos pesos una celda que había sido de la madre Catalina de San Jerónimo; la petición de licencia de compra fue del 20 de enero, y la licencia firmada por el arzobispo Aguiar y Seijas fue del 25 del mismo mes y año, y un tercer documento para la venta del 9 de febrero de 1692 (Cervantes, 1949, 47-51). Indudablemente el trámite fue expedito y pudo quedar en la autoridad contundente del arzobispo el negar esa aprobación, pero firmó generosamente; esto sucedía a diez meses de que sor Juana escribiera la Respuesta a sor Filotea, firmada el 1으 de marzo de 1691. Para algunos esta fecha es el cenit del conflicto que han conjeturado, pero el haber concedido a sor Juana la adquisición de la celda hace imposible el poder seguir afirmando el supuesto asedio arzobispal.

La celda comprada era exclusiva, con edificación de dos plantas "con sus altos y bajos", y podría ser visualizada así: la estancia y la cocina en la primera planta con espacio para que durmieran criadas y esclavas, y por una escalera se comunicaba a la celda en la segunda planta, con una cama, una mesita y una ventana, y acaso una estantería con libros. Todo sin cerrojos ni ventanas. En los conventos de vida Particular no había obligatoriedad de hacer las comidas en un refectorio y la comunidad religiosa únicamente se reunía para cumplir con los tiempos de oración, pero el resto del tiempo era libre. Las monjas jerónimas seguían la regla de San Agustín, laxa pero cuidadosa, íntima pero profunda. Aún se pueden ver hoy en la Universidad Claustro de sor Juana, 
los muretes de los cimientos de donde estaban las celdas particulares en el patio frente a la iglesia de San Jerónimo.

De las trescientos cincuenta monjas que entraron al convento a partir de la profesión de la fundadora, Isabel de San Jerónimo en 1586, hasta la última fecha asentada de 1767 para posteriormente iniciar un segundo tomo, las hermanas que permanecieron más años en el claustro fueron: 71 años (una monja); 66 años (tres monjas); 65 años (dos monjas); 63 años (cinco monjas); 62 años (dos monjas); 61 años (tres monjas) y 60 años (cuatro monjas). El Libro de Profesiones no incluye la fecha de nacimiento de las monjas, por lo que es imposible conocer su edad que tenían al morir. Hubo 256 hermanas que permanecieron en el claustro un tiempo mayor que sor Juana, es decir, un 73.14 \% de la muestra de 350 monjas permanecieron más años que sor Juana. Además, testifica que sor Juana tuvo que relacionarse con once prioras en el transcurso de su vida enclaustrada, en la secuencia de prioratos desde la vigésima cuarta priora a la trigésima cuarta (Schmidhuber y Peña, 2013):

1. La Madre María de San Miguel, tres años. Fecha del ingreso de sor Juana al convento de San Jerónimo.

2. La Madre Ana de Cristo, por segunda vez tres años.

3. La Madre María de San Miguel, otra vez cuatro años.

4. La Madre Catalina de San Jerónimo, tres años.

5. La Madre Beatriz de Jesús, tres años.

6. La Madre Ana de Jesús, tres años.

7. La Madre Juana de San Antonio, tres años.

8. La Madre Juana de Santa Ynés, tres años.

9. La Madre Juana del Sacramento priora y vicaria, tres años.

10.La Madre Andrea de la Encarnación priora y vicaria, tres años.

11.La Madre María de San Ignacio, tres años. Era priora cuando sor Juana murió.

Todas las prioras sabían leer y escribir y tenían que conocer principios básicos de administración y contabilidad, y se cautas en las relaciones humanas. La relación de sor Juana con las prioras debió 
ser balanceada porque le dieron tanta libertad que le permitió la recepción de correspondencia, el permiso para publicación y hasta cambiar de confesor, además se le respetó su tiempo para escribir.

Para comprender el ambiente social del Convento de San Jerónimo se elaboró un estudio que incluye información sobre las diez monjas que profesaron antes de sor Juana -1669-y diez monjas que profesaron posteriormente. Se trató de localizar la Fe de bautismo de cada una para comprobar la edad, ya que esa información no estuvo agregada a las actas de profesión que cada monja firmaba y que la priora testificaba con su firma. Con un gran esfuerzo de investigación se ha logrado presentar la Fe de bautismo de doce religiosas que profesaron previas a sor Juana y seis después, con la finalidad de corroborar la edad que tenían al profesar. Van citadas en el orden de profesión del Libro de Profesiones (Schmidhuber y Peña, 2015) y conviene aclarar que la fecha de nacimiento es información no utilizada en el siglo XVII porque no había documentación que lo testificara como la hay en el siglo actual. El primer documento en la vida de una persona era su Fe de bautismo que debía ser cercana a su fecha de nacimiento, debido a la alta mortalidad infantil y a la creencia cristiana que no había salvación sin el agua bautismal; esa fecha era únicamente recordada por la madre o la abuela. Como advertencia de la información abajo presentada, conviene aclarar que se incluyen la Fe de bautismo de las monjas que fue posible localizar que profesaron entre 1661 y 1679 (Schmidhuber y Peña 2018). De algunas otras también procedentes de matrimonio no fue posible dar con el registro de sus nacimientos, en algunos casos porque solamente se proporcionó el nombre del padre; y de aquellas "hijas de la iglesia" no hay manera de conocer ni su origen ni su edad: ${ }^{4}$

\section{FE DE BAUTIZO DE GREGORIA DE SORIA E ITA}

Parroquia del Sagrario de la ciudad de México,

Volumen 15 de bautismos de españoles, folio 73 vuelta, 1 de diciembre de 1644

\footnotetext{
${ }^{4}$ En el Libro de Profesiones del Convento de San Jerónimo se citan 16 "hijas naturales" entre las 330 profesas; esa circunstancia familiar no era impedimento para profesar en este convento. En la profesión de sor Juana, ella misma afirma puño y letra ser "hija legítima".
} 
En primero de diciembre de mil y seiscientos y cuarenta y cuatro años, de licencia del cura bautizó a Gregoria, hija de Simón de Soria y de doña Josefa de Ita. Fueron padrinos Diego Serralde y Catarina Beltrán. (Firmados). Una firma ilegible. Fray Antonio Vázquez. Profesión № 236: Con el nombre de Gregoria de San Antonio profesó el 17 de noviembre de 1661 a los dieciséis años de edad. Su muerte fue en 1688 tras 27 años de vida religiosa. Diez y siete años después de esta profesión, su hermana María profesó en 1678; tras la muerte de su hermana mayor, vivió sor Gregoria otros veintitrés años más hasta su muerte. Ambas profesaron a los 17 años.

\section{FE DE BAUTIZO DE NICOLASA HIDALGO Y SÁNCHEZ DE ALEDO}

Parroquia del Sagrario de la ciudad de México,

Volumen 14 de bautismos de españoles, folio 177 frente, 15 de mayo de 1642

En quince de mayo de mil y seiscientos y cuarenta y dos años, con licencia el cura bautizó a Nicolasa, hija de Gaspar Hidalgo y de Beatriz Sánchez de Aledo. Fue su padrino Alonso (N) Tamayo. (Firmados). Don Cristóbal Gutiérrez de Medina. Diego Rangel. Profesión № 237: Con el nombre de Nicolasa de San Juan profesó el 16 de abril de 1662 a los diecinueve años de edad. Su muerte fue en 1667 tras cinco años de religiosa.

\section{FE DE BAUTIZO DE FRANCISCA DALLO ANFOSSO}

Parroquia del Sagrario de la ciudad de México,

Volumen 13 de bautismos de españoles, folio 352 frente, 21 de octubre de 1638

En veintiuno de octubre de seiscientos y treinta y ocho años, presente el cura: bautizó a Francisca, hija de Andrés Dallo y de doña Margarita Alfonso [por Anfosso]. Fueron sus padrinos Antonio de Burgos y doña Luisa Sarmiento Rendón. (Firmados). Pedro Mejía. Fray Andrés de Posada. Profesión № 238: Con el nombre de Francisca de San Andrés profesó el 3 de mayo de 1662 a los veintitrés años de edad. Murió en la celebración de su profesión a los 27 años de monja. Fue cuñada del poeta Alonso Ramírez de Vargas. La fecha de su muerte fue escrita por la mano de sor Juana (Libro de Profesiones 191). 


\section{FE DE BAUTIZO DE MARÍA DE MELGAREJO Y GARCÍA SERRANO}

Parroquia del Sagrario de la ciudad de México,

Volumen 15 de bautismos de españoles, folio 183 frente, 8 de abril de 1646

En ocho de abril de mil y seiscientos y cuarenta y seis años, con licencia del cura semanero el padre maestro fray Jerónimo de Andrada bautizó a María, hija del doctor Juan de Melgarejo y de doña Juana García Serrano. Fue su padrino el licenciado Pedro Rincón de Ortega. (Firmados). Francisco de Villalobos y Mercado. Fray Jerónimo de Andrada. Profesión № 239: Con el nombre de María de la Anunciación profesó el 16 de agosto de 1662 a los dieciséis años de edad. Su muerte fue en 1682 tras veinte años de vida religiosa.

\section{FE DE BAUTIZO DE LUGARDA SÁNCHEZ DE CUENCA Y VÁZQUEZ DE APARICIO}

\section{Parroquia del Sagrario de la ciudad de México,}

Volumen 14 de bautismos de españoles, folio 296 vuelta, 29 de octubre de 1643

En veintinueve de octubre de seiscientos y cuarenta y tres años, con licencia del cura bautizó a Lugarda, hija de Francisco Sánchez de Cuenca y de doña Gabriela Vázquez. Fueron padrinos Andrés Sánchez de Aparicio y doña Eugenia de la Paz. (Firmados). Juan Sebastián Gutiérrez. Bachiller Juan Sánchez de Cuenca. Profesión № 240: Con el nombre de Lugarda Teresa de San Francisco profesó el 20 de enero de 1664 a los veinte años. Murió en 1692 tras 28 años de vida religiosa.

\section{FE DE BAUTIZO DE MARÍA DE BORJA Y REINOSO ALTAMIRANO}

Parroquia del Sagrario de la ciudad de México,

Volumen 15 de bautismos de españoles, folio 252 frente, 23 de febrero de 1647

En veintitrés de febrero de mil y seiscientos y cuarenta y siete años, con licencia del cura semanero bautizó a María, hija legítima del licenciado Diego de Borja Barco y de doña Mariana de Reinoso Altamirano. Fueron sus padrinos don Luis García (N) y doña Luisa Altamirano de Guevara. (Firmados). Don Cristóbal Gutiérrez de Medina. Fray Francisco Jiménez. Profesión № 241: Con el nombre de María de San Diego profesó el 19 de octubre de 1664 a los diecisiete años de edad. Murió en 1692 tras veintiocho años de vida religiosa. Era 
la mayor de tres hermanas que profesaron María en 1664, Agustina en 1669 y Lucía en 1672. Las tres hermanas tomaron el hábito a los diecisiete años. El Diario de Robles apunta el sábado 6 de octubre de 1685: "Esta noche, viendo los fuegos en la azotea de San Jerónimo, Juana, la hija mayor de Borja, le cayó un cohete en el pecho y del susto murió” (III: 437). El año no coincide con la defunción de ninguna de las tres monjas de ese apellido, indudablemente Juana visitaba a sus hermanas religiosas para observar los juegos pirotécnicos desde los techos del claustro y apareció el infausto cohete y la mató.

\section{FE DE BAUTIZO DE MARÍA DE TORRES MORENO Y ESTRADA (O DE VARGAS Y CORREA)} Parroquia del Sagrario de la ciudad de México,

Volumen 16 de bautismos de españoles, folio 84 frente, 16 de diciembre de 1648

En dieciséis de diciembre de mil y seiscientos y cuarenta y ocho años, con licencia del cura semanero: bauticé a María, hija del doctor Juan de Torres Moreno y de doña Casilda de Estrada. Fueron sus padrinos don Fernando de Santotís y Guevara, alcalde ordinario de esta ciudad, y doña Isabel de (N). (Firmados). Francisco Villalobos y Mercado. Fray Jerónimo de Andrada. Profesión № 243: Con el nombre de María de San Jerónimo profesó el 12 de enero de 1665 a los dieciséis años de edad. Murió en 1700 tras treinta y cinco años de monja.

\section{FE DE BAUTIZO DE MARÍA DE SORIA E ITA (HERMANA DE GREGORIA)}

\section{Parroquia del Sagrario de la ciudad de México,}

\section{Volumen 16 de bautismos de españoles, folio 227 frente, 20 de septiembre de 1650}

En veinte de septiembre de mil y seiscientos y cincuenta años, presente el cura semanero, el padre provincial de la orden de San Francisco y calificador del santo oficio fray Alonso de la Lima bautizó a María, hija de Simón de Soria y de doña Josefa de Ita, su mujer. Fue su padrino el capitán Esteban de Molina Mosquera. (Firmado). Fray Alonso de la Lima. Profesión № 246: Con el nombre de María de San Simón profesó el 12 de febrero de 1668 a los diecisiete años de edad. Murió en 1701 tras treinta y tres años de vida religiosa. Su hermana mayor había profesado en 1671 así que compartieron una década juntas en el convento, y tras la muerte 
de la hermana, sor María de San Simón pasó otros veintitrés años más hasta su muerte. Ambas habían profesado a los 17 años.

\title{
FE DE BAUTIZO DE MICAELA RODRÍGUEZ JARAMILLO Y JIMÉNEZ
}

\section{Parroquia del Sagrario de Puebla,}

Volumen 5, folio 472 frente, 9 de octubre de 1646

En nueve días del mes de octubre de mil seiscientos cuarenta y seis años bautizó con licencia de los señores curas el señor doctor don Miguel de Poblete, maestrescuela de esta santa iglesia, a Micaela, hija de Juan Rodríguez Jaramillo y de su mujer Catalina Jiménez. Fue su padrino don Francisco Romero. Y lo firmó. Fue su madrina María Velázquez, viuda. (Firmado). Don Miguel de Poblete. Profesión № 247: Con el nombre de Micaela de San Ildefonso profesó el 2 de octubre de 1668 a los veintidós años de edad. Murió en 1712 tras cuarenta y cuatro años de vida religiosa.

\section{FE DE BAUTIZO DE JUANA VEEDOR Y PALOMARES}

\section{Parroquia del Sagrario de la ciudad de México}

Volumen 16 de bautismos de españoles, folio 300 frente, 5 de octubre de 1651

En cinco de octubre de mil y seiscientos y cincuenta y un años, con licencia del cura semanero bautizó a Juana, hija de José Veedor, escribano real, y de doña Juana de Palomares. Fue su padrino el capitán Juan de Zelayeta. (Firmados). Doctor don Cristóbal Gutiérrez Medina. Diego de Valdés y Gamboa. Profesión № 248: Con el nombre de Juana de San José profesó el 2 de octubre de 1668 a los diecisiete años de edad. Murió en el 20 de octubre de 1705, casi diez años después de la muerte de sor Juana, tras treinta y siete años de vida religiosa.

\author{
FE DE BAUTIZO DE AGUSTINA DE BORJA Y REINOSO ALTAMIRANO (HERMANA DE MARÍA) \\ Parroquia del Sagrario de la ciudad de México, \\ Volumen 16 de bautismos de españoles, folio 278 frente, 24 de mayo de 1651
}


En veinticuatro de mayo de mil y seiscientos y cincuenta y un años, con licencia del cura semanero bautizó a Agustina, hija del licenciado Diego de Borja, abogado de esta real audiencia, y de doña Mariana Reinoso Altamirano. Fueron sus padrinos el contador don Francisco Tirol y Monte y doña Francisca Velasco y Bazán. (Firmados). Bachiller Diego de Villegas. Agustín de Mendiola. Profesión № 249: Con el nombre de Agustina Juana del Sacramento profesó el 29 de enero de 1669 a los diecisiete años de edad. Profesó el mismo año de sor Juana y coincidieron en el año de su muerte, el apunte de su fecha luctuosa fue de mano de sor Juana. Fue la primera en profesar de tres hermanas. Murió en 1695 tras veintiséis años de vida religiosa.

\section{FE DE BAUTIZO DE MARÍA DE VALDÉS Y CALDERÓN}

Parroquia del Sagrario de la ciudad de México,

Volumen 14 de bautismos de españoles, folio 97 vuelta, 8 de abril de 1641

En ocho de abril de mil y seiscientos y cuarenta y un años, con licencia del cura semanero bautizó a María, hija de don Agustín de Valdés y de doña Catalina de Calderón. Fue su madrina Juana de León. (Firmado). Diego Rangel. Profesión № 250: Con el nombre de María de la Concepción profesó el 21 de febrero de 1669 a los veintisiete años de edad. Su profesión fue la anterior a la de sor Juana. Murió en 1713 tras 44 años de vida religiosa.

SOR JUANA INÉS DE LA CRUZ, PROFESIÓN № 251 EL 24 DE FEBRERO DE 1669 Y MUERTE EL 17 DE ABRIL DE 1695.

\section{FE DE BAUTIZO DE LUCÍA DE BORJA Y REINOSO ALTAMIRANO (HERMANA DE MARÍA Y DE AGUSTINA)}

Parroquia del Sagrario de la ciudad de México,

Volumen 17 de bautismos de españoles, folio 201 vuelta, 28 de diciembre de 1654

En veintiocho de diciembre de mil y seiscientos y cincuenta y cuatro años, presente el cura semanero, el señor doctor don Simón Esteban Beltrán de Alzate, canónigo magistral de esta santa iglesia y catedrático de sagrada escritura en la real universidad de esta ciudad, bautizó 
a Luisa, hija del licenciado Diego de Borja, relator de la real audiencia, y de doña Mariana de Reinoso Altamirano. Fueron sus padrinos don Fernando Altamirano y doña Nicolasa de Olarte y Santoyo. (Firmado). Doctor Simón Esteban Beltrán. Profesión № 254: Con el nombre de Lucía de San José profesó el 9 octubre de 1672 a los diecisiete años de edad y fue la tercera en hacerlo de tres hermanas. Murió en 1719 con cuarenta y siete años de vida religiosa. Fue la última en morir de las tres hermanas, veinte años después de la muerte de la segunda y veintitrés de la primera.

JOSEFA DE RIOJA Y ARDUY. Con el nombre de Josefa de la Concepción profesó número 258 el 11 de febrero de 1675 . No fue posible encontrar la partida de su bautismo, aunque de acuerdo al promedio habría nacido entre mil seiscientos cincuenta y cuatro y mil seiscientos cincuenta y nueve probablemente como hija de la iglesia, pues sus padres Nicolás Antonio de Rioja y María de Arduy contrajeron matrimonio el veintisiete de mayo de mil seiscientos setenta y uno en la parroquia del Sagrario de la ciudad de México, apenas cuatro años antes de su profesión, tal vez con el objeto de legitimarla y a otras hijas en estado de matrimonio. Pudo haber sido un caso similar al de sor Juana. Murió en 1719 tras cuarenta y cuatro años de vida religiosa.

\section{FE DE BAUTIZO DE MARÍA ISABEL MORENO MONROY Y GUERRERO VILLASECA}

Parroquia del Sagrario de la ciudad de México,

\section{Volumen 19 de bautismos de españoles, folio 149 frente, 21 de julio de 1659}

En veintiuno de julio de mil y seiscientos y cincuenta y nueve años, con licencia del cura semanerobautizó a María Isabel, hija del capitán don Luis Moreno de Monroy y de doña Teresa Guerrero Villaseca. Fue su madrina doña Ana de Reza y Mendoza. (Firmado). Diego de Medina. Profesión № 260: Con el nombre de María Ysabel de San Juan profesó el 1o de septiembre de 1675 a los dieciséis años de edad. Murió en 1719 tras cuarenta y cuatro años de religiosa.

FE DE BAUTIZO DE TERESA DE TORRES Y VARGAS CORREA (HERMANA DE MARÍA) 


\section{Parroquia del Sagrario de la ciudad de México,}

Volumen 18 de bautismos de españoles, folio 31 frente, 17 de noviembre de 1655

En diecisiete de noviembre de mil y seiscientos y cincuenta y cinco años, presente el cura semanero, el señor don Jerónimo de Cervantes Casaús, canónigo de esta santa iglesia, bautizó a Teresa, hija legítima del doctor Juan de Torres y de doña Casilda de Vargas y Correa, su mujer. Fue su padrino el capitán Francisco de Ortega. (Firmado). Don Jerónimo de Cervantes. Profesión № 262: Con el nombre de Teresa de San Juan profesó el 11 de octubre de 1676 a los veinte años de edad. Muere en 1739 tras sesenta y tres años de vida religiosa.

\section{FE DE BAUTIZO DE FRANCISCA DE MORALES Y ARZOLA}

Parroquia del Sagrario de la ciudad de México,

\section{Volumen 18 de bautismos de españoles, folio 30 vuelta, 15 de noviembre de 1655}

En quince de noviembre de mil seiscientos y cincuenta y cinco, con licencia del cura semanero bautizó a Francisca, hija de José de Morales y de Ana de Arzola. Fueron sus padrinos Juan Ramiro de Morán y Francisca de Meza. (Firmados). El doctor don Diego de Torres. Luis del (N). Profesión № 269: Con el nombre de Francisca de Santa Teresa profesó el 28 de mayo de 1679 a los veintitrés años de edad. Muere en 1709 tras treinta años de vida religiosa.

Las diecisiete religiosas arriba citadas no pertenecían a estratos medio de la sociedad sino al estrato alto criollo, pero no todas sabían leer y escribir, lo que se sabe por comparación de la clara letra de quien escribió su Protesta de Fe contraponiéndose con la poca calidad de la mano firmante. Su edad al profesar fue la siguiente: tres de 16 años; siete de 17 años; una de 19 años; dos de 20 años; dos de veintidós; una de 23 y una de 27; cuyo promedio de edad fue 18:83 años. La edad de sor Juana al profesar el 24 de febrero de 1669 fue de 20 años, 3 meses y 12 días, número que queda arriba del promedio (1648). Al contar desde 1651, tendría tres años menos, es decir, 17 años, 3 meses y 12 días, por lo que queda abajo del promedio. Imposible inferir la verdadera edad de la monja con estos datos, pero innegablemente ayudan a esclarecer la verdad. Documentalmente sabemos que 
la entrada de sor Juana como postulanta al Convento de San Jerónimo fue el 8 de febrero de 1668, es decir, cuando ella tenía 19 años, 2 meses y 2 días con base a 1648, o con base a 1651, tres años menos, periodo tan importante en su vida secular. Los documentos citados pertenecen al archivo de la parroquia Sagrario de ciudad de México, iglesia barroca ubicada a un lado de la catedral; salvo una Fe de bautismo que proviene del Sagrario de Puebla de los Ángeles.

Como prueba de los festejos llevados a cabo queda un documento del siglo XVIII que atestigua la convivencia de la vida conventual de San Jerónimo en la visita del virrey Agustín de Ahumada y Villalón, marqués de Amarillas, el 19 de agosto de 1756. En la Hispanic Society de Nueva York está conservado este texto celebratorio que puede dar idea de un evento similar sucedido 61 años después de la muerte de sor Juana. Frederick Luciani $(2008$, p. 271) ha estudiado este documento:

Esta colectividad se refleja no sólo en la ejecución del festejo, sino también en la ficción dramática que éste elabora en las varias piezas teatrales. Es notable la inclusividad de estas piezas y el reconocimiento de la diversidad (estatus, clase social y raza) de esta comunidad de mujeres enclaustradas. El festejo barroco celebra la unidad jerárquica de la comunidad conventual.

La visita constó de la representación de una loa, un entremés, un sainete y una máscara con la actuación de las niñas que se educaban en el convento; la música estuvo a cargo de las religiosas. La dramaturgia fue del capellán del convento, Joaquín Barruchi, cuyos textos aluden cuatro veces a sor Juana. Fue un festejo lleno de alegría y color. El entretenimiento en el convento no era materia proscrita porque había numerosas celebraciones marcadas por el calendario litúrgico. Cada día tenía su aliciente que incluía alteración del horario, cambio de comida, actividades diferentes en el templo o el claustro; así como, en otros días, ayunos y abstinencias más silencio. Otro ejemplo de un festejo conventual está palpable en un manuscrito antiguo escrito por Joseph de la Barrera que relata la visita de la virreina María Luisa, condesa de Paredes al convento de Santa Clara (Farré, 2009). 
Los conventos eran lo más alejado de una cárcel, eran lugares de crecimiento y la creatividad no estaba vedada. Las religiosas que no sabían leer, aprendían. Era un ambiente más nutriente, como se dice hodierno, que algunos hogares de entonces y acaso también de hoy. El convento era un espacio de crecimiento espiritual pero también cultural. La mujer tenía la aprobación del cobijo grupal y dentro de los límites fijados por el Reglamento interno, las religiosas podían lograr satisfacer sus necesidades de autoestima y auto realización, acaso más que lo hubieran podido lograr en el mundo secular.

El claustro era una pequeña ciudad y la vocación religiosa obligara a la obediencia, la pobreza y castidad, pero había un grado de libertad permitido, la pobreza no era tan determinante que no pudieran tener lo necesario para vivir y hasta un poco más que las monjas podían ahorrar. El celibato no era sinónimo de soledad, la hermandad era una familia. Hoy orientamos nuestra mente en lo que llamamos objetivos, que hay que cumplir, pero en el siglo XVII, sobrevivir la infancia era más que un milagro y la juventud llegó a idealizar una vocación fervorosa que llevaba a las monjas a una beatitud temporal. Si Juana Inés hubiera preferido permanecer en el mundo, habría tenido una vida similar a la de sus hermanas y primas (Schmidhuber y Peña, 2016, p. 100-101), unas bien casadas y otras no tanto, la mayoría con multitud de hijos—su medio hermana Inés Ruiz Lozano tuvo diecisiete hijos — , pero más dificultades hubiera tenido para ser la primera mujer nacida en América que publicó un libro ${ }^{5}$ e imposible hubiera sido aprender tanto y escribir una obra literaria que hoy es una de las más preciadas de la literatura española.

\footnotetext{
${ }^{5}$ Sor Juana fue la primera mujer del cosmos hispánico que publicó un libro: Inundación castálida(Madrid, 1689). Dos mujeres la antecedieron, aunque no nacidas en América: En Northampton, Nueva Inglaterra, AnneBradstreet (16121672), donde su padre y su esposo fueron gobernadores de Massachusetts, a donde pasó a América en 1630; fue madre de ocho hijos; también fue llamada "la décima musa" en la publicación de su poesía: The Tenth Muse Lately Sprung Up in America (Londres, 1650); primera publicación de una mujer en el nuevo continente. En Nueva Francia hay que nombrar a Marie de I' Incarnation (1599-1672), nacida en Tours, Francia; fue casada, madre de un hijo y viuda a los 19 años; ingresó en el convento de las ursulinas en 1631 y viajó a Nueva Francia, en donde vivió hasta su muerte en Quebec; escribió diccionarios para los indios algonquin e iroquois; sus cartas constituyen un documento histórico del Canadá colonial.
} 


\section{Referencias}

Amerlinck, C. y Ramos, M. (1995). Conventos de monjas. Fundaciones en el México virreinal. México: Centro de Estudios de Historia de México CARSO.

Barruchi, J. (1756). Relación del festejo que a los Marqueses de las Amarillas les hicieron las Señoras Religiosas del Convento de San Jerónimo de México, México.

Cervantes, E. A. (1949). Testamento de Sor Juana Inés de la Cruz y otros documentos. México, Edición privada.

Farré, J. (2009). Festín plausible con que el convento de Santa Clara celebró en su felice entrada a la Exma. D. María Luisa, Condesa de Paredes, Marquesa de La Laguna y virreina de esta Nueva España. México: El Colegio de México.

Fernández, M. (2002). Cristóbal de Medina Vargas y la arquitectura salomónica en la Nueva España durante el siglo XVII. Monografías de Arte 27. México: Instituto de Investigaciones Estéticas, UNAM.

Luciani, F. (2008). “Fantasmas en el convento: una máscara en San Jerónimo (México, 1756)". En Arellano, I. y Rodríguez, J. A. (eds.). El teatro en la Hispanoamérica colonial. Madrid: Iberoamericana-Vervuert. 259-273.

Peñalosa, J. A. (1997). Alrededores de Sor Juana Inés de la Cruz. San Luis Potosí: Universidad Autónoma de San Luis Potosí.

Ramos, M. (2011). Voto y juramento de la Inmaculada Concepción en el convento de San Jerónimo de la ciudad de México. Siglo XVII al XIX. México: Centro de Estudios de la historia de México CARSO.

Ramos, M. (2013). "Los libros de Sor Juana". En Ramos, M. (Comp.). Vida conventual femenina (siglos XVI-XIX). México, Centro de Estudios de Historia de México CARSO.

Schmidhuber, G. y Peña, O. M. (2013). De Juana Inés de Asuaje a Sor Juana Inés de la Cruz. El libro de profesiones del convento de San Jerónimo de México. México: Instituto Mexiquense de Cultura y Frente de Afirmación Hispanista.

Schmidhuber, G. y Peña, O. M. (2016). Las familias paterna y materna de sor Juana Inés de la Cruz: Hallazgos documentales. México: Frente Afirmación Hispanista. Centro de Estudios de Historia de México CARSO y Editorial Escribanía. 
Schmidhuber, G. y Peña, O. M. (2018). Las redes sociales de sor Juana Inés de la Cruz. México: Bonilla Artigas.

Tapia, A. (1993). Carta de Sor Juana Inés de la Cruz a su confesor. Autodefensa Espiritual. Monterrey, Nuevo León: Producciones Al Voleo. 